\title{
Effects of Thermal Annealing and Film Thickness on the Structural and Morphological Properties of Titanium Dioxide Films
}

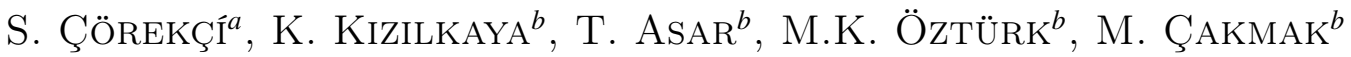 \\ AND S. ÖZÇELÍK ${ }^{b}$ \\ ${ }^{a}$ Department of Physics, Kirklareli University, 39160 Kırklareli, Turkey \\ ${ }^{b}$ Department of Physics, Gazi University, 06500 Ankara, Turkey
}

\begin{abstract}
Titanium dioxide $\left(\mathrm{TiO}_{2}\right)$ thin films having different thicknesses of 220, 260, and $300 \mathrm{~nm}$ were deposited onto well-cleaned $n$-type silicon substrates by reactive DC magnetron sputtering and annealed in the range of $200-1000^{\circ} \mathrm{C}$ in steps of $200^{\circ} \mathrm{C}$. The effects of thermal annealing and thickness variation on the crystalline quality and surface morphology of the films were investigated by X-ray diffraction and atomic force microscopy measurements. It was found that the film quality and morphology depend on the annealing temperature. $\mathrm{TiO}_{2}$ films exhibit a grain-like surface morphology. The root-mean-square roughness and grain size on the surface increase as a result of increasing film thickness.
\end{abstract}

PACS: 68.55.J-, 61.05.cp, 68.37.Ps

\section{Introduction}

Titanium dioxide $\left(\mathrm{TiO}_{2}\right)$ is one of the most studied metal oxides because of its applications such as photocatalysts [1-4], gas sensors $[5,6]$, solar cells $[7,8]$. As is known, $\mathrm{TiO}_{2}$ exists in amorphous form and in three different crystalline phases: rutile, anatase, and brookite [9]. Many of these applications depend on the structural and optical properties of $\mathrm{TiO}_{2}$ [4]. Post-deposition thermal annealing has an important influence on the properties of $\mathrm{TiO}_{2}$ films [9]. The purpose of this study is to determine the effects of thermal annealing and film thickness on the structural and morphological properties of $\mathrm{TiO}_{2}$ thin films deposited by using a reactive DC magnetron sputtering technique.

\section{Experimental details}

The $\mathrm{TiO}_{2}$ thin films having thicknesses of 220,260 , and $300 \mathrm{~nm}$ were deposited on $n$-type silicon (100) substrates by reactive DC magnetron sputtering. After deposition, the films were thermally treated in air for $2 \mathrm{~h}$ at 200 , $400,600,800$ and $1000^{\circ}$ C. Surface morphology and crystallinity of the films were characterized by X-ray diffraction (XRD) and atomic force microscopy (AFM) measurements. The AFM scans were carried out at $3 \mu \mathrm{m} \times$ $3 \mu \mathrm{m}$ surface areas.

\section{Results and discussion}

Figure 1 illustrates XRD patterns of the as-deposited and annealed films. As is seen, the films deposited by a reactive DC magnetron sputtering have polycrystalline titanium oxide ( $\mathrm{TiO}$ ) structures. After annealing at 200, 400 , and $600^{\circ} \mathrm{C}$, there appeared the $\mathrm{A}(004)$ and $\mathrm{R}(311)$ peaks in the anatase and rutile crystalline phases of $\mathrm{TiO}_{2}$, respectively. However, at temperatures above $600^{\circ} \mathrm{C}$, the anatase peak disappeared and the rutile phase was dominant.

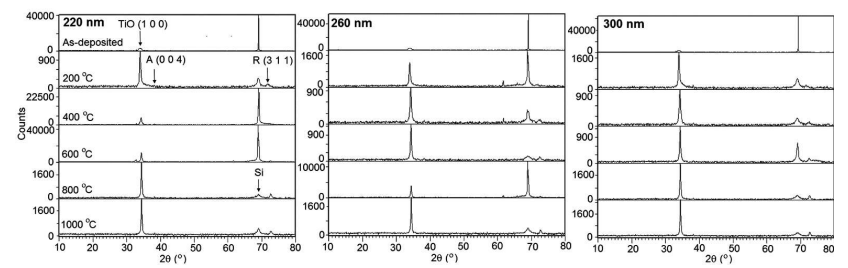

Fig. 1. XRD patterns of as-deposited and annealed films, which were identified as $\mathrm{TiO}(100)$ (JCPDS card no: 85-2084), $\mathrm{TiO}_{2} \mathrm{~A}(004)$ (JCPDS card no: 89-4921), Si (400) (JCPDS card no: 80-0018), and $\mathrm{TiO}_{2} \mathrm{R}(311)$ (JCPDS card no: 89-4920).

Figure 2 shows AFM scans of the as-deposited $\mathrm{TiO}_{2}$ films with different thickness. There appeared grains on the surfaces of the films. Similarly, Mathews et al. [4] observed the spherical features on the surface of a $\mathrm{TiO}_{2}$ film deposited on glass substrates by sol-gel dip coating technique and reported that they evaporated away during annealing.

On the other hand, the sizes of the grains on the surfaces of the films increased with film thickness. Further- 


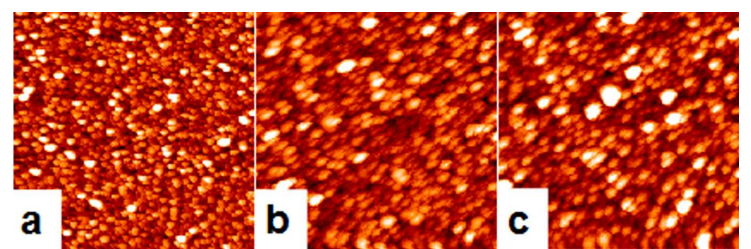

Fig. 2. AFM images of the as-deposited $\mathrm{TiO}_{2}$ films having thicknesses of (a) 220, (b) 260, and (c) $300 \mathrm{~nm}$. The surface RMS values of the films are $2.77,3.13$, and $3.42 \mathrm{~nm}$ for these scans of $3 \mu \mathrm{m} \times 3 \mu \mathrm{m}$, respectively.

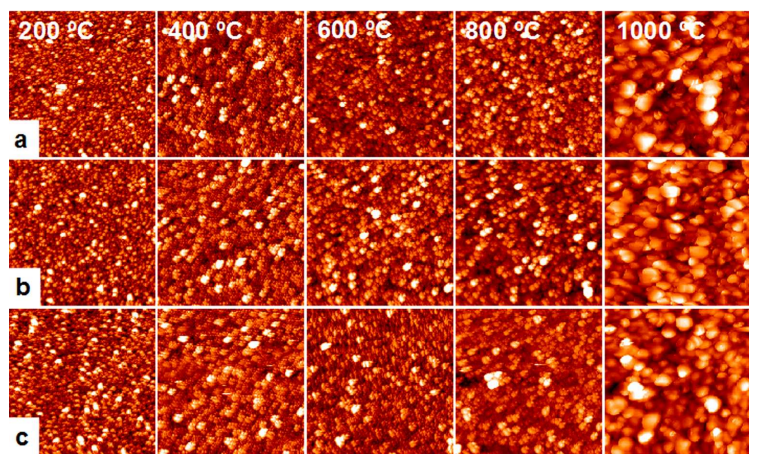

Fig. 3. AFM images of the annealed films having thicknesses of (a) 220, (b) 260, and (c) $300 \mathrm{~nm}$. The scan area is $3 \mu \mathrm{m} \times 3 \mu \mathrm{m}$.

more, the root-mean-square (RMS) roughnesses on the surfaces of the films having thicknesses of 220, 260, and $300 \mathrm{~nm}$ were obtained as $2.77,3.13$, and $3.42 \mathrm{~nm}$, respectively. From the RMS values, it can be seen that the film thickness increases the surface roughness, which is in agreement with the larger grains observed on the surfaces of thicker films.

Figure 3 shows AFM images of the $\mathrm{TiO}_{2}$ films with different thicknesses annealed at 200, 400, 600, 800, and $1000^{\circ} \mathrm{C}$. After $200^{\circ} \mathrm{C}$ annealing, no change was observed in the surface morphology of the films. However, the sizes of the grains decreased. The nanometer-size grains aggregated and a hillock-like structure on the surfaces of the films formed after $400{ }^{\circ} \mathrm{C}$.

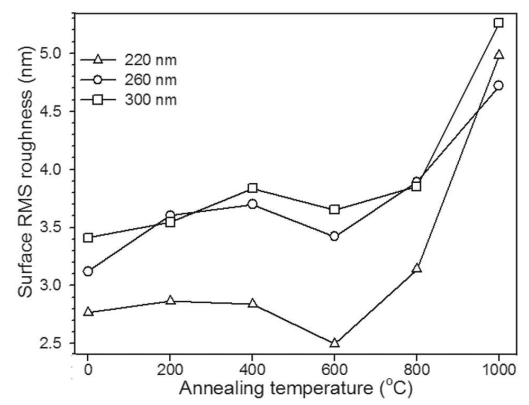

Fig. 4. The variation of the surface RMS roughness vs. the annealing temperature.
The surface RMS roughnesses of the films increased with increasing annealing temperature up to $400^{\circ} \mathrm{C}$, as shown in Fig. 4. After annealing at 600 and $800^{\circ} \mathrm{C}$, the surfaces of the films were covered by hillocks composed of agglomerated grains. The RMS roughness varied according to the densities and sizes of the hillocks and grains on the surfaces. In the case of annealing at $1000^{\circ} \mathrm{C}$, the films displayed hillocks with flat tops contrary to spherical grains or hillocks consisting of smaller grains observed at low temperatures, and higher RMS roughnesses. Furthermore, crystallite size of the films significantly increased as a result of completed coalescence process.

AFM observations clearly show that there is a remarkable change in surface morphology and roughness of the $\mathrm{TiO}_{2}$ films depending on the annealing temperatures and film thicknesses. The most likely reason for the dramatic topographic change is the recrystallization in the films due to thermal annealing which is in agreement with that reported by Mathews et al. [4]. On the other hand, the larger grains or hillocks on the surfaces of the films reveal an improvement in the crystalline quality of the $\mathrm{TiO}_{2}$ films, which is in agreement with XRD results.

\section{Acknowledgments}

This work has been supported by the Turkish State Planning Organization by project number 2011K120290.

\section{References}

[1] A. Fujishima, K. Honda, Nature 238, 37 (1972).

[2] T. Ihara, M. Miyoshi, M. Ando, S. Sugihara, Y. Iriyama, J. Mater. Sci. 36, 4201 (2001).

[3] M. Anpo, M. Takeuchi, J. Catal. 216, 505 (2003).

[4] N.R. Mathews, E.R. Morales, M.A. Cortes-Jacome, J.A.T. Antonio, Sol. Energy 83, 1499 (2009).

[5] K. Zakrzewska, M. Radecka, M. Rekas, Thin Solid Films 310, 161 (1997).

[6] Z. Seeley, Y.J. Choi, S. Bose, Sensors Actuators B 140, 98 (2009).

[7] O'Regan, M. Gratzel, Nature 353, 737 (1991).

[8] F. Li, Y. Gu, Mater. Sci. Semicond. Proc., in press, doi:10.1016/j.mssp.2011.04.008.

[9] D. Yoo, I. Kim, S. Kim, C.H. Hahn, C. Le, S. Cho, Appl. Surf. Sci. 253, 3888 (2007). 